\section{FORMAS DE SUBJETIVAÇÃO CONTEMPORÂNEAS E AS ESPECIFICIDADES DA GERAÇÃO Y}

\section{Present-day Forms of Subjectivity and the Specific Characteristics of $Y$ Generation}

\author{
Formas de Subjetivación Contemporáneas y las Especificidades \\ de la Generación $Y$
}

\section{Formes de Subjectivation Contemporaines et les Spécificités de la Génération $Y$}

\section{Resumo}

Este artigo teórico propõe a exploração das formas de subjetivação que fazem parte da contemporaneidade e investiga se existem especificidades subjetivas no recorte da juventude que tem sido chamado de Geração Y. Uma das principais características dos jovens da denominada Geração Y seria o uso constante de tecnologias digitais, circunstância que teria acompanhado todo o seu desenvolvimento. A partir de uma revisão teórica sobre as modalidades de subjetivação, articulada com a psicanálise e o conceito de Geração Y, o artigo considera que os integrantes desta geração são agentes e sujeitos do tempo contemporâneo e, assim, participam da produção de subjetividades. A partir desta perspectiva, são discutidas conexões entre as características subjetivas já reconhecidas da contemporaneidade e aquelas que podem estar emergindo a partir da Geração Y, de modo a conferir-lhe uma especificidade, apesar da padronização e estereótipos que o conceito de geração confere-lhe.

Palavras-chave: formas de subjetivação; Geração Y; contemporaneidade; modernidade; psicanálise.

\section{Abstract}

This theoretical article proposes an exploration of subjectivity forms that are part of contemporaneity and investigates whether there are subjective characteristics in the youth cut that has been called Y Generation. One of the main characteristics of young people from the so-called Y Generation would be the constant use of digital technologies, a circumstance that would have accompanied throughout its development. From a theoretical review about the modalities of subjectivity articulated with psychoanalysis and the concept of Y Generation, this paper considers that the members of this generation are agents and subject of contemporary time and thus participate in the production of subjectivities. From this perspective, connections are discussed between the subjective characteristics already recognized of the contemporaneity and those that may be emerging from the Y Generation, in order to give it specificity, despite the standardization and stereotypes that the concept of generation gives it.

Keywords: forms of subjectivation; $Y$ generation; contemporaneity; modernity; psychoanalysis.

\section{Resumen}

Este artículo teórico propone la explotación de las formas de subjetivación que hacen parte

\section{Artigo Original}

\author{
André Verzoni ${ }^{(1)}$ \\ Carolina Lisboa ${ }^{(2)}$
}

1) Psicólogo, Psicanalista, Mestre em Psicologia e doutorando na Pontifícia Universidade Católica do Rio Grande do Sul (PUCRS). Professor na Escola Factum. Membro da APPOA (Associação Psicanalítica de Porto Alegre).

2) Psicóloga, Doutora em Psicologia na Universidade Federal do Rio Grande do Sul (UFRGS). Professora da Pontifical Pontifícia Universidade Católica do Rio Grande do Sul (PUCRS). Coordenadora do grupo de pesquisa RIVI (Relações interpessoais e violência: contextos clínicos, sociais, educacionais e virtuais.
Recebido em: 11/05/2015

Revisado em: 29/08/2015

Aceito em: 10/10/2015 
de la contemporaneidad e investiga si existen especificidades subjetivas en el recorte de la juventud que ha sido chamada Generación Y. Una de las principales características de los jóvenes de la Generación Y es el uso constante de tecnologías digitales, circunstancia que les acompañaría por todo su desarrollo. A partir de una revisión acerca de las modalidades de subjetivación, articulada con el psicoanálisis y el concepto de Generación Y, el artículo considera que los integrantes de esta generación son agentes y sujetos del tiempo contemporáneo y, así, participan de la producción de subjetividades. A partir de esta perspectiva, son discutidas conexiones entre las características subjetivas ya reconocidas de la contemporaneidad y aquellas que pueden estar surgiendo a partir de la Generación Y, de modo a darle una especificidad, a pesar de la estandarización y estereotipos que el concepto de generación le confiere.

Palabras clave: formas de subjetivación; Generación Y; contemporaneidad; modernidad; psicoanálisis.

\section{Résumé}

Cet article théorique propose l'exploration des formes de subjectivation qui font partie de la contemporainéité et investigue s'il y a des spécificités subjectives dans le cadre de la jeunesse appelé la Génération Y. Une des principaux caractéristique des jeunes de la Génération Y serait l'usage fréquant des technologies digitaux, condition qui aurait suivi tout son développement. À partir d'une révision théorique sur les modalités de subjectivation, articulée à la psychanalyse et au concept de Génération Y, l'article considère que les intégrants de cette génération sont les agents et les sujets du temps contemporain et, ainsi, participent à la production de subjectivités. À partir de ce point de vue sont discutées des connexions entre les caractéristiques subjectives déjà connues de la contemporanéité et celles qui sont en train d'émerger à partir de la Génération Y, d'une façon à attribuer à elle une spécificité, malgré la padronization et stéréotypes que le concept de génération porte.

Mots-clés: formes de subjectivation; Génération Y; contemporanéité; modernité; psychanalyse.

São praticamente infinitas as concepções de sujeito e as suas diferentes formas de subjetivação que as sociedades, a partir da cultura e do conhecimento, criaram e ainda criam para evoluírem, entenderem-se e explicarem-se. Desde as primeiras civilizações, em meio à construção desta série interminável de concepções, sociedade e sujeito promovem mudanças mútuas que produzem efeitos drásticos ou graduais, surpreendentes ou previsíveis. Neste ambiente em constante transformação, a forma como a sociedade se organiza ou se desorganiza tem importantes conseqüências sobre a subjetividade daqueles que a compõem. Nesse cenário, os sujeitos podem se realizar ou se anular, assim como podem confrontar, abster-se ou construir, a partir de algo que seja da sua singularidade, um lugar específico no status quo que os envolve. Como resultado deste processo, emergem as novas formas de subjetivação que são determinantes para a natureza das percepções, visões de mundo e as formas de bem-estar e sofrimento psíquico dos sujeitos da sociedade contemporânea (Bauman, 2001, 2008, 2009, 2011; Birman, 2007a; Foucault, 1984; Kehl, 2002).

As sociedades do final do século XX e do início do século XXI — e as formas de subjetivação por elas produzidas - promoveram e continuam a promover novas maneiras de viver e interpretar a vida. Ao abordarmos especificamente a contemporaneidade, é possível observar o surgimento do conceito de Geração Y, que reúne em torno de si uma categoria de sujeitos e suas formas de subjetivação singulares (Birman, 1997; Bleichmar, 2004/2010; Foucault, 1984) um agrupamento de indivíduos nascidos entre 1980 e 2000 que tem como característica principal o uso constante de tecnologias digitais, circunstância que teria acompanhado todo o seu desenvolvimento. A denominação Geração Y (Alsop, 2008; Bauman, 2011; Howe \& Strauss, 2000; Prensky, 2001a; Stein, 2013) emerge como uma forma de classificação que confina os seus integrantes a um espaço subjetivo restrito, em razão dos preconceitos e estereótipos que lhes são impostos, assim como pode ser capaz de identificar e descrever subjetividades específicas. Este artigo, ao propor a exploração das relações entre a contemporaneidade e as modalidades de subjetivação, tem como objetivos discutir se há especificidades subjetivas e de que forma estas especificidades se manifestam nos jovens que, na atualidade, tem sido chamados de Geração Y. Para seguir nesse sentido, a psicanálise, articulada em conjunto com o conceito de formas de subjetivação (Birman, 1997; Bleichmar, 2004/2010; Foucault, 1984; Potte-Bonneville, 2004; Weinmann, 2006), serve como base para a exploração da Geração Y enquanto fenômeno da contemporaneidade.

Este artigo teórico antecede um estudo empírico realizado com sujeitos que podem ser considerados integrantes da Geração Y (Verzoni, 2015). Como uma forma de investigação prévia e que oferece parâmetros para a pesquisa empírica, este artigo propõe uma discussão sobre as características subjetivas e psíquicas dos jovens da Geração Y, que são descritas pela literatura (Alsop, 2008; Bauman, 2011; Bergman, Fearrington, Davenport, \& Bergman, 2011; Howe \& Strauss, 2000; Myers \& Sadaghiani, 2010; Prensky, 2001a; Stein, 2013) em relação às teorias sobre as formas de subjetivação contemporâneas (Birman, 1997, 2007a, 2007b, 2013a, 2013b, 2013c; Dockhorn \& Macedo, 2008; Kehl, 2002; Macedo \& Silva, 2012; Mansano, 2010; Melman, 2002; Roudinesco, 2000). Para atingir esse propósito, este trabalho teórico coloca este recorte da juventude na condição de herdeiros e agentes da contemporaneidade e visa desconstruir estereótipos gerados 
pelo uso do termo Geração Y enquanto senso comum.

\section{Geração Y: Compreendendo o Conceito}

O conceito de geração - assim como o de nação, classe e gênero - pode ser entendido como uma forma de categorização. É claro que entre os integrantes de uma mesma geração são encontradas diferenças individuais significativas, mas isto não impede o estabelecimento de algumas relações e similaridades que permitem um agrupamento baseado nas características compartilhadas. $\mathrm{O}$ conceito de geração implica que os seus integrantes sejam destituídos, ao menos em parte, da sua condição de indivíduos absolutamente singulares, de forma a excluir momentaneamente algumas das suas qualidades específicas (Bauman, 2011).

Grande parte dos jovens da sociedade contemporânea tem sido denominada como Geração Y (Alsop, 2008; Howe \& Strauss, 2000). Também chamada de Millennials ou Globalists, esta geração é composta por homens e mulheres nascidos entre os anos de 1980 e 2000. De forma a refletir a diversidade de seus hábitos e interesses, os Millennials possuem várias outras designações: NetGeneration, Generation Next e iGeneration (Alsop, 2008). Millennials é o nome escolhido por Howe e Strauss (2000) para definir a geração que encerrou o seu ciclo de nascimentos no final do último século.

O final do século XX e o início do século XXI têm sido caracterizados pelo uso da tecnologia digital. A evolução dos computadores e suas ferramentas tiveram influência determinante sobre a formação da nova geração de pessoas: os nativos digitais (Digital Natives). Ao contrário dos imigrantes digitais (Digital Immigrants), os nativos digitais já nasceram imersos nos múltiplos recursos criados pela informática, os quais aprenderam a explorar de forma espontânea. Os imigrantes digitais, originários do mundo "analógico", são obrigados a realizar grande esforço para aprenderem a usar a tecnologia digital, uma vez esta não pertence a sua "natureza". Os nativos digitais, nascidos nas últimas décadas do século XX e início do século XXI, desenvolveram-se com jogos de computador, videogames, câmeras, reprodutores de música digitais, email, internet $\mathrm{e}$ celulares como elementos fundamentais de sua rotina. Por terem nascido na era digital - e por isso expostos desde o início às várias tecnologias -, estes jovens pensam, percebem e reagem de forma diferente em relação aos seus predecessores, os imigrantes digitais (Prensky, 2001a). Como conseqüência da exposição constante ao ambiente digital, os nativos digitais podem ter desenvolvido uma forma específica de pensar e raciocinar, o que lhes conferiu novas habilidades cognitivas - diferentes daquelas dos imigrantes. No entanto, Prensky (2001b) sugere que os nativos digitais podem apresentar prejuízos na capacidade de reflexão e de produzir generalizações elaboradas a partir de experiências.

Devido à escassez de estudos empíricos sobre características e formas de subjetivação da Geração Y, a grande quantidade de referências não científicas como livros, revistas, blogs, jornais e sites podem oferecer importantes contribuições teóricas e práticas aos pesquisadores. Além disso, o grande volume destes materiais demonstram a relevância social de se estudar esta geração - ainda que muitas vezes apresentem mitos, distorções e estereótipos. Apesar de não contemplarem o rigor científico que seria desejável, estas publicações são capazes de, pelo menos, orientar a exploração do universo psíquico destes sujeitos (Myers \& Sadaghiani, 2010).

Entre as principais características atribuídas à Geração Y, assim como aos nativos digitais, encontra-se a constante conexão com equipamentos ou dispositivos digitais (alguns dos preferidos são os iPods e iPhones). Entretanto, a Geração Y, por ser um conceito mais amplo e que abarca mais características que a denominação nativos digitais, apresenta outras qualidades. Entre elas, podem ser destacadas especificidades na relação desses jovens com seus pais, que ocupam um papel central em sua vidas. Para essa geração, os pais mantém-se como fontes constantes de orientação e aconselhamento, mesmo que os filhos já tenham conquistado grande parte de sua independência. Além disso, são descritos como jovens que conferem uma grande importância ao status representado pelos nomes e marcas, seja de empresas, universidades ou produtos para consumo. Os jovens da Geração Y são apresentados como indivíduos que sentem-se confortáveis ao trabalhar em grupo e ao executar várias tarefas ao mesmo tempo, além de atribuir importância para o equilíbrio entre as obrigações profissionais e a vida pessoal. Descrita como otimista e impaciente, esta geração pode se incomodar quando é classificada como excessivamente individualista, alguns dos seus estereótipos mais freqüentes no senso comum. Os pais dos jovens desta geração, por sua vez, teriam educado e criado (ou ainda educam e criam) seus filhos como se fossem suas "crianças-troféu", ou seja, para que estes satisfaçam o narcisismo deles próprios. Colocados nesta posição, os jovens da Geração Y teriam sobre si a grande responsabilidade de corresponder às expectativas que foram-lhes endereçadas, devendo, para tanto, apresentar uma elevada performance e desempenho nas atividades que se propõem a realizar (Alsop, 2008).

A reportagem The Me Me Me Generation. The new greatest generation: why millennials will save us all, publicada na revista Time (Stein, 2013), afirma que estes jovens são reconhecidos pela sociedade como narcisistas, superficiais, autocentrados, preguiçosos e exageradamente confiantes em suas habilidades. Mesmo que se trate de uma matéria publicada em periódico não científico, cabe aqui a discussão acerca do impacto deste conceito na cultura, 
na subjetivação e no comportamento da sociedade para com estes jovens adultos. Sejam estas características, descritas na reportagem, qualidades ou defeitos, as mesmas representariam uma geração de jovens que pode causar importantes transformações na sociedade contemporânea. Os Millenials muitas vezes podem ser alvo de estigmas e estereótipos, circunstâncias que justificam estudos científicos para o esclarecimento acerca da subjetividade destes indivíduos. Apesar de compartilharem diversos atributos, entre eles o fato de terem nascido entre 1980 e 2000, os Millenials de cada país tem as suas próprias particularidades. Entretanto, em razão da ampla circulação da informação proporcionada pela tecnologia - que a tornou mais acessível para todos —, a Geração Y compartilhou influências globalizadas de forma intensa, o que a teria tornado mais homogênea, sobretudo quando comparada às suas antecessoras. Como resultado desta imersão na tecnologia, os Millennials podem apresentar comportamento aditivo quanto ao uso das redes sociais virtuais e das diferentes ferramentas de comunicação virtual, de forma a sentirem-se compelidos a estar sempre on line para acompanhar e atualizar, incessantemente, as novidades, mensagens e publicações - o que pode implicar em elevados níveis de sofrimento psíquico e inibições nas interações sociais. A geração $M e$ Me Me pode demonstrar pouca capacidade de empatia e dificuldades para entender diferentes pontos de vista, uma das conseqüências do individualismo (Alsop, 2008; Bauman, 2011; Howe \& Strauss, 2000; Stein, 2013). Algumas das características atribuídas à Geração Y encontram ressonâncias nas descrições do contexto contemporâneo realizadas por Birman (2007b), no qual os sujeitos privilegiam o desempenho, esforçam-se em apresentar uma performance, supervalorizam a imagem de si e deixam de lado as trocas e as interlocuções com outros indivíduos. Privados de um contato além do superficial e atrelados exclusivamente aos ideais individuais, os sujeitos da contemporaneidade vêemse cercados pela agressividade, violência e irritabilidade. $\mathrm{Na}$ contemporaneidade, a separação da adolescência em relação à infância e à idade adulta se torna cada vez mais tênue. Como conseqüência deste novo contexto, as diferenças entre as gerações encontram-se cada vez mais suprimidas (Birman, 2007b).

Um estudo sobre a Geração Y (Bergman, Fearrington, Davenport, \& Bergman, 2011) investigou as relações entre o narcisismo e o uso das redes sociais virtuais por parte desta geração. Estes jovens, ao usarem a tecnologia das redes sociais, podem solicitar a amizade de outras pessoas e recebem convites para, por sua vez, tornarem-se "amigos" de outros usuários. Um dos principais recursos das redes de relações virtuais é o "perfil”, que pode ser moldado de acordo com as características que o seu titular gostaria de tornar disponível aos outros usuários. Assim, como se fosse uma "estrela" do seu próprio filme (ou vida), o jovem pode mostrar aos outros onde está, o que está fazendo e o que está pensando, seja publicando fotos, alterando informações do seu perfil ou escrevendo mensagens. Ao comparar o narcisismo e o uso das redes sociais, o estudo apontou a importância atribuída pela Geração Y no que se refere à necessidade de conhecer o maior número de pessoas possível nas redes sociais. A relação entre o narcisismo e o uso das redes sociais permite inferir que os jovens que integram a Geração Y não buscam as redes sociais virtuais para chamar a atenção de outras pessoas e reforçar a sua autoestima, características que constituem alguns dos seus estereótipos mais comuns. O grande dispêndio de tempo em relações virtuais protagonizado por parte desta geração pode ser, simplesmente, uma forma de substituir os meios de comunicação mais tradicionais - como carta, telefone ou email - por outras tecnologias mais modernas (Bergman et al, 2011). Ou então, pode ser uma manifestação específica do contexto contemporâneo, no qual impera o individualismo e prosperam o narcisismo e o exibicionismo. Estas circunstâncias favorecem o enfraquecimento, ou até mesmo o desaparecimento, das relações que são capazes de ultrapassar a superficialidade entre as pessoas (Birman, 2007a). Para investigar as razões do interesse por parte dos Millennials no uso das redes sociais, seria fundamental a realização de pesquisas que compreendam outras motivações e características psíquicas desta geração (Bergman et al, 2011).

\section{Formas de Subjetivação}

Didaticamente, o processo de construção das diferentes formas de subjetivação pode ser considerado uma "disputa" que coloca de um lado o indivíduo e, de outro, a cultura e a sociedade. A subjetivação é um meio utilizado pelo sujeito para que este, justamente, não se assujeite - ao menos parcialmente - em relação às influências que o cercam. Entretanto, subjetivar-se não significa construir algo que seja próprio e exclusivo do indivíduo. A construção da subjetividade dá-se no espaço entre o sujeito e a cultura em que ele está inserido (Weinmann, 2006).

Para Freud (1927/1996), conceito de cultura e civilização - vital para a compreensão das formas de subjetivação - consiste-se na totalidade das realizações que separam a humanidade da sua condição animal e primitiva. De forma geral, a cultura acarreta para cada indivíduo que dela participa um benefício e um prejuízo fundamental. O ganho reside no controle das forças e das variações da natureza, que resultam em alguma estabilidade e segurança que são divididas de forma coletiva. O prejuízo, por sua vez, encontra-se na restrição da liberdade individual determinada pelas regras, leis e costumes implementados em nome da estabilidade da civilização. Para ser preservada, a cultura deve ser protegida dos interesses individuais de 
seus integrantes - sobretudo quando estes ameaçam a sua continuidade e manutenção. Para esta tarefa, a civilização conta com regulamentos, instituições, ordens e coerções que atuam no controle das ações e do psiquismo dos seus integrantes. A tríade composta por frustração, proibição e privação traça o roteiro do controle que a cultura estabelece sobre os indivíduos. A frustração reside na impossibilidade da satisfação de um desejo, pulsão ou instinto por parte do sujeito. A proibição é a regra ou convenção que não permite esta satisfação. A privação é a condição que se estabelece em decorrência da proibição. Nesta dinâmica entre forças que por vezes podem ser contrárias — o desejo individual e a preservação da cultura - são construídas as formas de subjetivação que, ao contemplarem ambos os pólos, fazem com que ambos sofram modificações e sejam constantemente renovados (Freud, 1927/1996).

Para a prática e teoria psicanalítica, a subjetividade não ocupa o lugar principal, este encontra-se reservado aos processos inconscientes. Entretanto, a subjetividade faz-se presente de forma significativa nos fenômenos psíquicos e não deve ser negligenciada, uma vez que desempenha a importante função de amparar o sujeito e protegê-lo dos aspectos desintegrativos do inconsciente - aos quais o sujeito não tem pleno acesso, mas que o influenciam ou até mesmo o determinam (Bleichmar, 2004/2010). As formas de subjetivação criam o espaço necessário para que o indivíduo possa fazer parte da cultura em que vive e tenha uma existência viável — sem ter que desfazerse totalmente da sua singularidade. Para alcançar esta integração, cabe ao sujeito criar um "estilo de existência" que contemple a sua especificidade e o contexto cultural (Birman, 1997). Ainda que relacionados, inconsciente e subjetividade não devem ser confundidos. A subjetividade refere-se ao fazer-se sujeito no espaço-tempo, constituindo uma intencionalidade exterior. Os processos inconscientes, apesar de mutáveis e, em certa medida, específicos à cada indivíduo, apresentam uma constância e regularidade que permitem o estabelecimento de algumas regras ou leis a respeito do seu funcionamento. A subjetividade, por outro lado, é mais suscetível às mudanças históricas e culturais e representa, em certo sentido, uma defesa ou amparo do sujeito em relação às condições da civilização em que vive. O fato da psicanálise sustentar que existe algo que antecede o próprio pensamento do sujeito, a saber, o inconsciente, não retira o seu interesse na forma com a qual o indivíduo se subjetiva, ou seja, torna-se sujeito em relação à cultura ou civilização. A estabilidade da subjetivação pode exercer a importante função de manter a organização do psiquismo, equilíbrio que pode ser ameaçado pela "dessubjetivação" ou por qualquer forma de subjetivação que não seja validada pela cultura (Bleichmar, 2004/2010). A produção de subjetividade, que encontra-se supervisionada pelos controles exercidos pela civilização, gera influências que definem como os indivíduos devem ser e se comportar para que possam fazer parte de uma determinada cultura. Como contrapartida à inclusão, o sujeito deve sustentar alguns preceitos, valores e ideais que não são necessariamente seus (Freud, 1927/1996). Apesar da primazia da cultura, cabe ao sujeito explorar as falhas, vazios e contradições sociais a fim de criar novas formas de subjetivação para, assim, tornar-se menos sujeito e mais agente em relação ao tempo e lugar em que vive (Bleichmar, 2004/2010).

O conceito de subjetivação nos remete a Foucault (Potte-Bonneville, 2004) que, durante grande parte de sua obra, propôs-se a refletir e a examinar como os sujeitos se transformam e se constituem como tais em diferentes tempos e lugares. Para atingir este objetivo, Foucault trilhou o caminho que poderia ser chamado de a "história do sujeito" (Potte-Bonneville, 2004). A tarefa de delinear a história da subjetividade pode ter, como referência inicial, o período helenístico (323 a.C. a 146 a.C.), tempo no qual emergiu a "cultura de si". Esta modalidade primordial de subjetivação era caracterizada por uma preocupação e, por conseqüência, uma ocupação do sujeito em relação a si mesmo e a respeito das formas com as quais poderia conduzir a sua vida (Foucault, 1984). A adesão ou não à cultura de si não era imposta, ou seja, o Estado, as leis e a religião não desempenhavam papel determinante neste sentido, cabia ao próprio sujeito decidir se optaria por este estilo de vida. Nem todos escolhiam viver de acordo com esta forma de subjetivação, uma vez que a mesma compreendia uma série de obrigações e renúncias. A disciplina era indispensável para que o sujeito alcançasse uma existência com elevados ideais estéticos e éticos e vivesse uma bela vida para os padrões da época (Mansano, 2010).

De acordo com esta maneira de conduzir a existência humana — de renúncias em nome de aquisições —, a constituição das formas de subjetivação torna-se necessariamente influenciada por demandas morais. Os preceitos morais, na forma de código formal e imperativo, transformam-se em moral ao passarem pelo crivo do sujeito que, ao agir, passa a utilizar o código em relação à si mesmo, ou seja, a refletir a respeito dele e a transformá-lo internamente. Neste exercício moral, o sujeito é obrigado a examinar a si mesmo, controlar-se, aperfeiçoar-se e modificar-se - ação na qual prospera alguma forma de subjetivação. Não é à toa que, antes de abordar as formas de subjetivação, faz-se necessário considerar o "modo de sujeição", ou seja, de que maneira o sujeito age e reflete em relação ao código moral (Foucault, 1984) que, por sua vez, é parte vital da cultura, que o utiliza como ferramenta para conservar-se (Freud, 1927/1996).

Para explorar a construção da subjetividade — seja ela contemporânea ou de outro período histórico - faz-se necessário uma investigação a respeito das possibilidades que são disponibilizadas ao sujeito para que ele possa fazer parte de uma cultura específica (Bleichmar, 2004/2010). Em linhas gerais, a contemporaneidade pode ser considerada 
um reflexo de fenômenos que tornaram-se predominantes a partir dos anos 80 do século XX, a saber: busca pela igualdade de direitos entre as pessoas, globalização, neoliberalismo, aumento da concentração de riqueza, desemprego e exclusão social (Birman, 2013a). É válido ressaltar que os sujeitos que podem ser incluídos na Geração $\mathrm{Y}$ nasceram e se desenvolveram durante este período histórico e conviveram com seus ideais e vicissitudes (Alsop, 2008; Bauman, 2001; Howe \& Strauss, 2000); circunstância que nos permite inferir que esta geração pode representar um terreno fértil para a manifestação das novas formas de subjetivação.

\section{Formas de Subjetivação Contemporâneas}

$\mathrm{Na}$ contemporaneidade, as formas de subjetivação assumem condições inéditas e adquirem qualidades originais com uma intensidade notável (Bauman, 2011, 2001; Birman, 2007a) Neste contexto de mudanças e instabilidade nas modalidades de fazer-se sujeito, os jovens que podem ser incluídos na Geração Y emergem como um importantes representantes das mudanças na subjetividade, seja tentando se desvencilhar dos estereótipos que lhe são atribuídos, seja buscando a sua especificidade no espaçotempo em que vivem.

As formas de subjetivação contemporâneas (e também da última década do século XX e da primeira década do século XXI) podem colaborar com a reflexão a respeito de características subjetivas que são capazes de apontar a especificidade da Geração Y, bem como discutir os estereótipos que lhe são atribuídos. Para realizar uma exploração que contemple as formas de viver a vida, pensamentos, comportamentos e desejos destes jovens, pode se revelar vital investigar em que tipo de contexto eles se desenvolveram e quais mudanças estão construindo. $\mathrm{O}$ aprofundamento nesse sentido configura-se em importante fator a ser considerado na investigação sobre as formas de fazer-se sujeito que podem caracterizar os integrantes da Geração Y.

Birman (2007a) sustenta que o mundo contemporâneo deve ser classificado como apenas mais uma etapa da modernidade, e não como um período absolutamente novo, circunstância que o permitiria ser chamado de pós moderno. Neste novo segmento da modernidade, encontramos um ambiente conturbado no qual os sujeitos, ao tomarem parte da sua agitada movimentação, enfrentam dificuldades para reagir de uma maneira satisfatória ao que lhes é apresentado. Sobrecarregados pela grande variedade e velocidade dos estímulos da contemporaneidade, os instrumentos interpretativos dos indivíduos podem se revelar insuficientes. Para Bauman (2001), a modernidade, em sua versão contemporânea, pode ser resumida em duas características principais: em primeiro lugar, o desmantelamento de qualquer ideal passível de ser compartilhado socialmente - uma conseqüência da queda da primazia conferida ao coletivo e ao comunitário em proveito do individualismo e, em segundo lugar, a desregulamentação e a privatização, adventos que prosperaram sob o pretexto de oferecer ao indivíduo o suposto domínio sobre as suas escolhas e a impressão de que possui a liberdade para definir o que lhe fará feliz.

O conceito de modernidade líquida (Bauman, 2001) ilustra a época em que vivemos atualmente. Para analisar este contexto de forma mais aprofundada, é necessário saber que o tempo ocupa um lugar fundamental. $\mathrm{O}$ mundo contemporâneo é líquido porque é volúvel (por ter a capacidade de tomar diferentes formas) e porque realiza mudanças e deslocamentos livremente (superando barreiras sem dificuldades) - como a água que transpõe o que se coloca no seu caminho. Antes da modernidade líquida, quando os sólidos predominavam, o mais importante era o espaço. Na época dos líquidos, o tempo passa a ser o elemento mais confiável uma vez que, se for respeitado, permite ao menos algum tipo de apreensão sobre a subjetividade, tão difícil de ser feita em razão de seu caráter transitório. Na era da solidez, o tempo era facilmente controlado e tinha menos importância, já que a característica principal dos sólidos era justamente a manutenção do seu lugar. A subjetividade que se estabelecia de determinada forma, assim permanecia por bastante tempo. Para os sólidos, a importância recaía sobre o espaço, uma vez que estes mantinham a sua condição por um longo período, o que garantia-lhes um caráter estável. A modernidade líquida e sua inundação subjetiva oferecem condições ilusórias para que as pessoas escolham o estilo de vida que acreditam desejar. $\mathrm{O}$ abandono de padrões, códigos e regras que orientavam e restringiam a vida das pessoas fundamentou-se na promessa de emancipação cuja característica principal seria a possibilidade de autoconstrução (Bauman, 2001).

$\mathrm{Na}$ contemporaneidade, as mudanças nas formas de subjetivação ocorrem mais rapidamente do que em qualquer outra época (Bauman, 2011). Em razão desta transitoriedade, as teorias, descrições e interpretações precisam ser constantemente revisadas e renovadas (Bauman, 2001). Outro fator que reforça esta inconstância, é a fragmentação da subjetividade: as formas de subjetivação contemporâneas dividiram-se em uma infinidade de unidades. Esta fragmentação pode servir como matriz para a elaboração de subjetividades que moldam-se sob a influência da desconstrução, assim como possibilita um tipo de específico de subjetivação — absolutamente variado, caótico e com elementos contraditórios que não se relacionam entre si. A fragmentação subjetiva é caracterizada, principalmente, por conduzir os indivíduos à inconsistência psíquica e falta de referências (Birman, 2007a). Na sociedade do início do século XXI, as dificuldades e equívocos, que inevitavelmente ocorrem 
durante o percurso social do indivíduo, muitas vezes são vividos como inadequados e podem fazer com que o sujeito se desorganize psiquicamente. Alijado de uma referência constante, o sujeito contemporâneo busca incessantemente afirmação ou confirmação sobre si mesmo e, quando não a encontra, revela a sua fragilidade psíquica (Melman, 2002). O esvaziamento, as mudanças constantes nas formas de subjetivação e até mesmo a dessubjetivação, podem ser determinantes para as mais diversas manifestações de sofrimento psíquico da contemporaneidade (Bleichmar, 2004/2010).

No mundo contemporâneo é possível observar, principalmente nos grandes centros urbanos, importantes mudanças na subjetividade dos jovens brasileiros e de outros países do mundo. Entre elas, encontramos um crescimento da agressividade e da violência, sobretudo na faixa de idade que compreende os 16 anos e os 24 anos (Birman, 2013b). O comportamento violento, ao contrário do que o senso comum poderia afirmar, não é exclusividade das classes sociais menos favorecidas: ele também se faz presente nas classes mais altas. As formas de subjetivação violentas sustentam-se sobre a ideia de que o outro é sempre um inimigo em potencial, ideia que é reforçada pelo ambiente competitivo criado pelo capitalismo (Birman, 2013b). Para Kehl (2002), os valores mais cultivados na sociedade contemporânea são a liberdade, a autonomia individual e a valorização narcísica do sujeito $\square$ características que reforçam o contexto de disputa. Com o predomínio do individualismo, a transmissão entre as diferentes gerações pode tornar-se restrita ou até mesmo ser interrompida, o que pode fazer com que o sujeito se abstenha de um compromisso com a sua própria descendência e filiação. Esta falta de reconhecimento familiar é facilmente transmitida para a natureza das relações sociais as quais o sujeito é capaz de estabelecer que, por sua vez, tornam-se mais restritas e empobrecidas (Kehl, 2002).

Antes do advento da modernidade líquida (Bauman, 2001), os sujeitos se orientavam a partir de "grupos de referência" aos quais se identificavam ou haviam sido assimilados. Na era dos líquidos, os sujeitos passaram a navegar à deriva no oceano da comparação universal (Bauman, 2001). A sociedade contemporânea obriga os seus sujeitos a gozarem sem, no entanto, apresentar-lhes qualquer limite quanto a este imperativo (Melman, 2002) e sem oferecer-lhes a possibilidade da separação entre o prazer e o bem - não no sentido de bem supremo, mas o bem de cada um. Neste mal entendido protagonizado pelos indivíduos, o prazer pode se confundir, ou até mesmo se restringir, ao desejo individual de cada sujeito (Kehl, 2002).

Assim como o individualismo se apresenta de forma cada vez mais maciça na cultura atual, os fenômenos coletivos tornam-se cada vez mais escassos. Os jovens, que estão entre aqueles que mais têm acesso às formas de comunicação e deslocamento modernas, privilegiam as relações do espaço virtual - disponível a partir da tecnologia digital e suas infinitas conexões e alcance em detrimento do local, que se restringe à comunidade e ao território em que o indivíduo habita. As possibilidades oferecidas pelo espaço local nem sequer se comparam com as múltiplas opções proporcionadas pelo ciberespaço. Em razão desta desigualdade de forças, o local torna-se insignificante enquanto que o virtual, o verdadeiro lar dos mais adaptados à modernidade, adquire cada vez mais importância e se torna predominante (Bauman, 2009). Neste contexto de predomínio de relações virtuais, destacaramse as manifestações políticas e populares "presenciais" ocorridas na Grécia em novembro e dezembro de 2008 fenômenos de colaboração entre pessoas e grupos (Birman, 2013b). É válido lembrar que, entre os que protestavam contra as condições econômicas e a repressão policial, a grande maioria era composta por jovens. A explicação para este predomínio, contrário à ideia de uma juventude individualista, reside no fato de que esta geração seria a que mais sofreria com as novas condições de seu país (Birman, 2013b). Apesar deste episódio de colaboração e convívio entre jovens, pode-se afirmar que a subjetividade moderna apresenta severas dificuldades para lidar com a diferença e a singularidade, elementos que constituem a base das interações humanas. Incapaz de reconhecer-se na diferença em relação ao outro e, assim, legitimá-la, o sujeito moderno isola o que lhe é dissonante. Neste predomínio de relações espelhadas, nas quais os sujeitos se reconhecem apenas nas similaridades, o empobrecimento psíquico é inevitável. Privado da interação genuína com o seu semelhante, o sujeito moderno vincula-se ao outro somente se este reforça o seu narcisismo, que já encontra-se exacerbado. O outro das relações modernas, constrito a assumir a condição de objeto, serve ao sujeito apenas para que este satisfaça as suas necessidades, o que caracteriza uma perversidade que se instala nas relações entre as pessoas (Birman, 2007a). Na superficialidade das relações mediadas pela anulação das diferenças, o indivíduo, da mesma forma que não reconhece o outro, não é, por sua vez, reconhecido - circunstância que o priva de grande parte do acesso à sua singularidade. Para constituírem-se como sujeitos, os seres humanos devem estar inseridos na cultura e, portanto, é inevitável que os seus semelhantes desempenhem uma função fundamental em sua constituição (Bleichmar, 1997/2010).

\section{Subjetivação e o Sofrimento Psíquico Contemporâneo}

As construções subjetivas contemporâneas - e as mudanças psíquicas que acarretam sobre os sujeitos podem apresentar-se de forma consistente no campo clínico da Psicologia. Na prática clínica, as novas formas de subjetivação exigem uma postura que pelos menos 
faça frente e responda - e não necessariamente satisfaça -, às demandas psíquicas contemporâneas. Entre as mudanças apresentadas pela contemporaneidade encontrase o enfraquecimento, ou até mesmo a inexistência, de um conflito interno que coloque o sujeito em questão. Em seu lugar, proliferam-se os conflitos concretos ou embates externos, que contaminam o ambiente social e as relações interpessoais (Birman, 2007a). Nesse contexto, é mais importante triunfar na disputa e comparação direta com o outro do que obter uma satisfação que seja própria ao indivíduo. Dessa forma, as relações humanas tornam-se cada vez mais empobrecidas, superficiais e fugazes, o que apenas aumenta o isolamento e a solidão do sujeito da atualidade (Dockhorn \& Macedo, 2008). A cultura do narcisismo, vivenciada pelos pais dos jovens contemporâneos pode ter sido transmitida aos seus filhos, assim como pode ter causado-lhes prejuízos psíquicos. O excesso narcísico dos pais pode estar relacionado à privação afetiva decorrente das mudanças nos padrões familiares que ocorreram durante a modernidade. Entre elas, o abandono, por parte da mulher, de uma posição eminentemente materna para uma condição que passou a privilegiar outros interesses e atividades sociais - enquanto que o homem, ao ocupar o lugar de pai, pouco teria modificado a sua função (Birman, 2013b).

Entre as causas do mal-estar contemporâneo, apresentase a falta de um projeto particular que apare o sofrimento psíquico residual e inerente ao sujeito. A ausência de uma meta ou plano que não se resuma às possibilidades que estão imediatamente ao alcance do indivíduo - e que seja cultivada, modificada e se renove ao longo do tempo -, afasta-o da esperança de que o mal-estar possa se extinguir em algum momento. Uma das formas que os seres humanos têm de suportar e combater o que lhes aflige hoje é a promessa de que, no futuro, o que os incomoda deixará de existir (Bleichmar, 1997/2010). Como conseqüência da desesperança, a depressão torna-se uma das manifestações psíquicas predominantes da sociedade moderna e apresenta, como principais sintomas, a tristeza, a apatia, a busca de identidade e o culto a si mesmo. A disseminação generalizada dos estados depressivos é agravada, sobretudo, pelas novas opções e liberdades ofertadas aos indivíduos pelos avanços sociais e tecnológicos. Em razão da grande quantidade de possibilidades disponíveis, os integrantes da sociedade depressiva sofrem ainda mais por não saberem como aproveitá-las. O tempo - que prolonga-se em razão do aumento da expectativa de vida, do ócio e do desemprego - paradoxalmente torna-se cada vez mais insuficiente para comportar todas as possibilidades que estão ao alcance dos indivíduos (Roudinesco, 2000). A sociedade contemporânea revela-se uma formidável fonte de novas necessidades que são impostas aos sujeitos que dela participam. Com a velocidade impressionante ditada pelo mundo globalizado e respondendo ao surgimento de cada uma destas novas necessidades, fontes de satisfação são criadas e vendidas (e este é o verbo mais adequado) a um preço justo, ou, às vezes, nem tanto. Os sujeitos contemporâneos, com referências distorcidas e sem orientação, podem tornar-se incapazes de diferenciar o que é básico e o que é supérfluo em suas vidas, buscam objetos e experiências artificiais que saciem aquilo que vivenciam como seus verdadeiros desejos. Neste sistema onde impera o circuito necessidadesatisfação, prospera a lógica de mercado que basta a si mesma e que, por esta razão, repete-se à exaustão e traz cada vez mais mal-estar (Bauman, 2008).

$\mathrm{Na}$ contemporaneidade, a imagem ocupa papel fundamental nas relações entre as pessoas. Na sociedade do espetáculo (Debord, 1967/1997), aparentar é tão importante, ou até mesmo mais, quanto ser. Em torno do espetáculo, unificam-se os sujeitos. Porém, para tanto, estes devem abandonar a sua singularidade para incorporarem esta forma de subjetivação (Debord, 1967/1997). Em concordância com a primazia da imagem, é possível observar que, entre os jovens que vivem nas grandes metrópoles, há uma grande valorização atribuída ao corpo forte, definido e musculoso (Birman, 2013b). A forma física bem trabalhada é de suma importância pois encontrase diretamente relacionada com o conceito de beleza. Para os jovens, os músculos avantajados representam uma demonstração de força e prestígio perante os seus pares. A virilidade, assim, confunde-se com a força física, que pode ser demonstrada a partir da aparência que é apresentada aos outros. Este estereótipo de masculinidade sinaliza justamente o enfraquecimento ou ausência da virilidade, ou seja, retrata a falta de segurança e "potência" (Birman, 2013b). De modo a reforçar a primazia da performance, os critérios de êxito ou fracasso contemporâneos são baseados na disputa direta com o outro. Assim, o "ser" perdeu espaço para o desejo de receber admiração. Em uma sociedade narcísica, o entendimento entre duas partes antagônicas se torna extremamente difícil, o que faz com que a convivência e as trocas sejam deixadas de lado e, no lugar dela, prosperem as mais diversas formas de atuação. $\mathrm{O}$ grande prejuízo resultante da atuação é a alienação do sujeito que a pratica, o que o faz se distanciar cada vez mais do outro e de si mesmo. Estas e outras transformações culturais às quais os sujeitos contemporâneos estão expostos trazem conseqüências tanto intrasubjetivas como intersubjetivas (Macedo \& Silva, 2012). Na contemporaneidade, os laços sociais e interpessoais perdem força e a construção da individualidade emerge como atividade principal, ou única, por parte do indivíduo. A individualidade, entretanto, reserva pouco espaço para o afeto, o amor a convivência com outras pessoas. No lugar das trocas interpessoais, desponta a identidade profissional como premissa única para a inserção na vida pós moderna (Birman, 1997).

O sofrimento psíquico da contemporaneidade, que utiliza maciçamente o corpo para se apresentar, denota o 
enfraquecimento dos processos de simbolização disponíveis aos sujeitos. Como manifestação desta pobreza psíquica, proliferam-se as compulsões - em seu sentido de ação que se sobrepõe a sujeito, retirando-lhe autonomia — referentes à alimentação, substâncias tóxicas e objetos de consumo (Birman, 2007b). O sujeito da contemporaneidade, na busca de algo que mitigue o seu sofrimento psíquico, tende a privilegiar tratamentos farmacológicos que visam equilibrar a química do organismo - em detrimento de uma terapêutica que exija a sua implicação em relação ao seu próprio sofrimento. Na tentativa de contornar o sofrimento, o sujeito pode ignorar a sua própria condição subjetiva, esvaziando-a e promovendo, assim, a dessubjetivação que pode tornar-se um fenômeno de massa (Dockhorn \& Macedo, 2008). O espaço para a criatividade e reconstrução da sua história, elementos que possibilitariam ao sujeito reinventar-se a partir de algum ideal de vida, torna-se cada vez mais escasso. Com a restrição deste campo psíquico, ramifica-se o mal-estar que transforma a esperança em ilusão (Bleichmar, 1997/2010).

\section{Considerações Finais}

A Psicanálise e a Psicologia são constantemente postas à prova diante das novas formas de subjetivação. As subjetividades são influenciadas pelas constantes mudanças das condições históricas e sociais que cercam o sujeito, circunstância que faz com que os paradigmas da Psicanálise, assim como da Psicologia, sejam obrigados a encontrar maneiras de responder às essas variações. Para se manterem sólidas perante às novas demandas e condições psíquicas que surgem em razão de diferentes contextos históricos e sociais, que produzem distintas subjetividades e tipos específicos de sofrimento psíquico, a Psicanálise e a Psicologia necessitam expor-se a este cenário caracterizado pela instabilidade.

A investigação do fenômeno da Geração Y - ao ser aprofundado a partir de estudos empíricos que investiguem se existe uma especificidade das suas formas de subjetivação, e que sejam capazes de descrevê-las e compreendê-las à luz da contemporaneidade - pode também proporcionar a desconstrução de alguns mitos e estereótipos atribuídos a este recorte da juventude. Em uma análise mais aprofundada e conectada com a realidade, é possível que revele-se necessário considerar que os preconceitos impostos a estes jovens tenham mais relações com algumas características da contemporaneidade do que esta juventude em si.

Este estudo procurou explorar as novas formas de subjetivação e estabelecer relações destas com o recorte da juventude que tornou-se conhecido como Geração Y. A partir da investigação e a obtenção de uma visão mais apurada sobre esse conjunto de sujeitos que compartilham algumas características comuns, novos aspectos subjetivos da contemporaneidade podem surgir, assim como uma especificidade que caracterize este grupo da juventude. Colocada nessa condição, a Geração Y pode ser um "laboratório" privilegiado das manifestações da subjetividade contemporânea, tão difícil de apreender em razão das suas constantes mudanças e instabilidade.

\section{Referências}

Alsop, R. (2008). The trophy kids grow up. San Francisco: Jossey Bass.

Bauman, Z. (2001). Modernidade líquida. Rio de Janeiro: Zahar.

Bauman, Z. (2008). Medo líquido. Rio de Janeiro: Zahar.

Bauman, Z. (2009). Confiança e medo na cidade. Rio de Janeiro: Zahar.

Bauman, Z. (2011). 44 cartas do mundo líquido moderno. Rio de Janeiro: Zahar.

Bergman, S., Fearrington, M., Davenport, S., \& Bergman, J. (2011). Millennials, narcissism, and social networking: what narcissist do on social networking sites and why. Personality and individual diferences, 50, 706-711. doi: 10.1016/j.paid.2010.12.022

Birman, J. (1997). Estilo e modernidade em psicanálise. São Paulo: Editora 34.

Birman, J. (2007a). Mal-estar na atualidade: a psicanálise $e$ as novas formas de subjetivação. Rio de Janeiro: Civilização Brasileira.

Birman, J. (2007b). Laços e desenlaces na contemporaneidade. Jornal de psicanálise, 40(72), 47-62. http://pepsic.bvsalud.org/pdf/jp/v40n72/ v40n72a04.pdf

Birman, J. (2013a). Sujet et pouvir dans la contemporaneité. Recherches en en psychanalyse, (15), 11-22. doi: 10.3917/rep.0150011

Birman, J. (2013b). La condition adolescent dans la contemporanéité: une lecture de la jeunesse dans la société brésilienne. Figures de la psychanalyse, (25), 63-83. doi: 10.3917/fp.025.0063

Birman, J. (2013c). Os paradigmas em psicanálise são comparáveis? Sobre o mal-estar, a biopolítica e os jogos de verdade. Tempo Psicanalítico, Rio de Janeiro, 
45(I), 147-178. http://pepsic.bvsalud.org/pdf/tpsi/ v45n1/v45n1a11.pdf

Bleichmar, S. (2010). Límites y excesos del concepto de subjetividad en psicoanális. In S. Bleichmar, $L a$ subjetividad en riesgo (pp. 91-97). Buenos Aires: Topía. (Trabalho original publicado em 2004)

Bleichmar, S. (2010).Un modo de pensar nuestro tiempo. In S. Bleichmar, La subjetividad en riesgo (pp. 19-22). Buenos Aires: Topía. (Trabalho original publicado em 1997)

Debord, S. (1997). A sociedade do espetáculo. Rio de Janeiro: Contraponto. (Trabalho original publicado em 1967)

Dockhorn, C.N.B.F., \& Macedo, M. (2008). A complexidade dos tempos atuais: reflexões psicanalíticas. Argumento psicologia, 54(26), 217-224. http://www2.pucpr.br/ $\mathrm{reol} /$ index.php/pa?dd1 $=2496 \& d d 99=$ view

Focault, M. (1984). História da sexualidade 2: o uso dos prazeres. Rio de Janeiro: Graal.

Freud, S. (1996). O futuro de uma ilusão. In Obras Psicológicas Completas de Sigmund Freud (Vol. XXI). Rio de Janeiro: Imago. (Trabalho original publicado em 1927)

Howe, N., \& Strauss, W. (2000). Millennials rising: the next great generation. New York: Vintage Books.

Kehl, M. R. (2002). Sobre Ética e Psicanálise. São Paulo: Companhia das Letras.

Macedo, M. M. K., \& Silva, F. C. F. (2012). Inquietações no cenário contemporâneo: reflexões psicanalíticas sobre a masculinidade. In M. M. K. Macedo, \& B.G. Werlang (Org.), Psicanálise e Universidade (pp. 66-81). Porto Alegre: Edipucrs.

Mansano, S. R. V. (2010). Sujeito, subjetividade e modos de subjetivação na contemporaneidade. Revista de Psicologia da UNESP, 8(2). http://www2.assis.unesp. br/revpsico/index.php/revista/article/viewFile/139/172

Melman, C. (2002). L’homme sans gravité. Paris: Denoël.

Myers, K., \& Sadaghiani, K. (2010). Millennials in the workplace: a comunication perspective on millennials organizational relationships and perfomances. Journal of Business and Psychology, 25(2), 225-238. doi: 10.1007/s10869-010-9172-7
Potte-Bonneville, M. (2004). Michel Foucault, l'inquietude de l'histoire. Paris: Presses Universitaires de France.

Prensky, M. (2001a). Digital Natives, Digital Immigrants. On the Horizon, 9(5), 1-6.

Prensky, M. (2001b). Do they really think differently? On the Horizon, 9(6), 1-9.

Roudinesco, E. (2000). Por que a Psicanálise? Rio de Janeiro: Zahar.

Stein, J. (2013, maio). The Me Me Me Generation. The new greatest generation: why millennials will save us all. Time, 25-37.

Verzoni, A. (2015). Formas de subjetivação da Geração $Y$. Dissertação de Mestrado, Programa de Pós Graduação em Psicologia, Pontifícia Universidade Católica do Rio Grande do Sul (PUCRS), Porto Alegre, Rio Grande do Sul, Brasil.

Weinmann, A. (2006). Dispositivo: um solo para a subjetivação. Psicologia \& Sociedade, 18(3), 16-22.

\section{Endereço para correspondência:}

André Verzoni

Endereço: Av. Carlos Gomes, n 1001, sala 701, Porto Alegre/RS.

E-mail: andre.verzoni@gmail.com

\section{Endereço para correspondência:}

Carolina Lisboa

Endereço: Pontifícia Universidade Católica do Rio Grande do Sul, Av. Ipiranga, nº 6681 - Prédio 11, Porto Alegre/RS. E-mail: carolina.lisboa@pucrs.br 